\title{
TIPS: a reality in Brazil
}

D'Albuquerque LAC, Carnevale FC. TIPS: a reality in Brazil. Arq Gastroenterol. 2012;49(2):97-8.

HEADINGS - Portasystemic shunt, transjugular intrahepatic. Hypertension, portal. Brazil.

Transjugular intrahepatic portosystemic shunt (TIPS) is an artificial channel within the liver that establishes communication between the inflow portal vein and the outflow hepatic vein. It is used to treat portal hypertension complications like esophageal varices bleeding or ascites. TIPS indication has become more frequent mainly in groups that perform liver transplants because it has been indicated as a bridge for liver transplantation.

In the paper published in this issue of ARQUIVOS de GASTROENTEROLOGIA ${ }^{(1)}$, a high incidence of technical complications was observed. This series shows an initial experience, started many years ago charactering different expertises and devices, during the period here analyzed. Nowadays technical complications like cervical hematoma, pneumothorax and hemothorax could be avoided with the use of ultrasound guidance to perform the transjugular approach. This may be result of the learning curve associated to the group performing TIPS.

Although major complications can occur during or as a result of TIPS creation, they are generally uncommon and are reduced with increased operator experience.

Published rates for individual types of complications are highly dependent on patient selection and are based on series comprising several hundred patients, which is a volume larger than most individual practitioners are likely to treat. The overall procedure threshold is more appropriate for use in a QI program. Major complications occur in 5\% of patients.

Concerning stent fracture with migration to the pulmonary artery, to the right ventricle and to the right atrium more experience in the stent deployment and the use of e-PTFE-covered stents is associated with reduction in the incidence of TIPS dysfunction and recurrence of complications.

Another issue is the efficacy of e-PTFE-covered TIPS in controlling bleeding and thus preventing further clinical deterioration. The FDA has approved the e-PTFE-covered stent for TIPS and its indication has been proved by many authors to reduce variceal rebleeding and TIPS stenosis/dysfunction rates than bare stents. In addition, the use of e-PTFE-covered stent is less expensive due to the less need for re- interventions to treat stenosis and thrombosis of the shunts ${ }^{(2)}$.

TIPS has been associated with encephalopathy episodes. But, in a recent publication, the early use of TIPS was not associated with an increase in the number or severity of episodes of hepatic encephalopathy. The study was specifically designed to show whether an early decision to use TIPS, and based on clinical criteria, could improve the prognosis for patients with variceal bleeding who were at high risk. It was found that in patients treated early with e-PTFE-covered stents TIPS, the risks of failure to control bleeding and of variceal rebleeding were reduced. This may result of clinical evaluation and indication before TIPS. Previous studies evaluating the role of TIPS in the prevention of recurrent variceal bleeding clearly showed that TIPS reduces the rebleeding rate but increases hepatic encephalopathy without improving survival.

Recently, the decision to perform TIPS has been done based on the measurement of hepatic venous pressure gradients, a test that is not widely available in many institutions, especially under emergency conditions.

Recent studies have shown that TIPS should not be used as the initial treatment in patients with Child-Pugh class A disease, since the rates of medical treatment failure and mortality are low among such patients. Although the risks of treatment failure and death can be higher in patients with Child-Pugh class $\mathrm{C}$ disease than in those with class B disease. Furthermore, in patients with Child-Pugh class $\mathrm{C}$ disease or class B disease with active bleeding who were admitted for acute variceal bleeding, the early use of TIPS with an e-PTFE-covered stent was associated with significant reductions in the failure to control -bleeding, in rebleeding, and in mortality, with no increase in the risk of hepatic encephalopathy ${ }^{(3)}$.

Although the TIPS clinical indication it is now well established in the portal hypertension treatment it is always recommended to have a multidisciplinary approach to establish the right patient and moment to proceed with before liver transplantation.

\section{Luiz Augusto Carneiro D'ALBUQUERQUE ${ }^{1}$ Francisco Cesar CARNEVALE ${ }^{2}$}

\footnotetext{
'Serviço de Transplante de Fígado e Órgãos Abdominais, Hospital das Clínicas da Faculdade de Medicina da Universidade de São Paulo (HC-FMUSP):
} ${ }^{2}$ Serviço de Radiologia Intervencionista - HC-FMUSP, São Paulo, SP, Brasil. 
D’Albuquerque LAC, Carnevale FC. TIPS: uma realidade no Brasil. Arq Gastroenterol. 2012;49(2):97-8.

DESCRITORES - Derivação portossistêmica transjugular intra-hepática. Hipertensão portal. Brasil.

\section{REFERENCES}

1. Funes FR, Silva RCMA, Arroyo Jr PC, Duca WJ, Silva AAM, Silva RF. Mortality and complications in patients with portal hypertension who underwent transjugular intrahepatic portosystemic shunt (TIPS) - 12 years experience. Arq Gastroenterol. 2012;49:143-9.

2. García-Pagán JC, Caca K, Bureau C, Laleman W, Appenrodt B, Luca A, Abraldes
JG, Nevens F, Vinel JP, Mössner J, Bosch J; Early TIPS (Transjugular Intrahepatic Portosystemic Shunt) Cooperative Study Group. Early use of TIPS in patients with cirrhosis and variceal bleeding. N Engl J Med. 2010;362:2370-9.

3. Haskal ZJ, Martin L, Cardella JF, Cole PE, Drooz A, Grassi CJ, McCowan TC, Meranze SG, Neithamer CD, Oglevie SB, Roberts AC, Sacks D, Silverstein MI, Swan TL, Towbin RB, Lewis CA; Society of Interventional Radiology Standards of Practice Committee. Quality improvement guidelines for transjugular intrahepatic portosystemic shunts. J Vasc Interv Radiol 2003;14:S265-70. 